\title{
Measurement of Force Requirement for Manually Operated Chaff Cutter Measurements of Mechanical Parameters
}

\author{
Akki Sathish*, Bangi Nirmala, Rathnapuram Ashwini, \\ Gopathi Anusha and Ch. Balachand
}

Departmentof Farm Machinery and Power Engineering, College of Agricultural Engineering, Sangareddy, Telangana, India

*Corresponding author

\section{A B S T R A C T}

\section{Keywords}

Chaff cutter performance, Force requirement and Hand cranking capabilities

Article Info

Accepted:

07 September 2020 Available Online: 10 October 2020
Manually operated chaff cutter is one of the most common agricultural equipment being used by marginal farmers particularly farm women. A chaff cutter (Sonkhiya Agricultural Industries, Jaipur) was evaluated with 3 different age group female workers using three different types of locally available fodders (three replications for each fodder) which are regular feed to the animals to support additional income to the farmers of southern region of India. In this paper, the measurement of the mechanical parameters like force requirement, hand cranking capabilities, length of cutting \& moisture content of different fodders are reported. Force requirement was increased gradually due to the presence of high moisture content of fodders and large size diameter of fodders. Hand cranking capabilities at load conditions gradually decreased compare to at no-load conditions.

\section{Introduction}

In India, the rural women play an extraordinary role in agriculture and other agro based activities. The daily work schedule of rural women is very much challenging and vigorous. Usually women carryout different agricultural activities like transplanting, weeding, harvesting, threshing and chaff cutting. The farmers in rural and tribal areas of Telangana are marginal farmers. They own 2-4 cattle as per their need. As the fodder consumption for one adult bullock is $10-12$ $\mathrm{kg} /$ day and for cow or buffalo is $7-10 \mathrm{~kg} /$ day, the average fodder requirement is about 24 to $45 \mathrm{~kg} /$ day. So a single manual chaff cutter is sufficient for chopping the fodder for a marginal farmer. Hence it is needed to evaluate the chaff cutter for optimizing the operating parameters and recommend to the farmers. So three different age grouped women (Subjects $\mathrm{P}_{1}, \mathrm{P}_{2} \& \mathrm{P}_{3}$ ) were selected to refine mechanical measurements of women on chaff cutter. The main aim of the study is to evaluate the force requirement for cutting three different fodders, Hand cranking 
capabilities of women and capacity of chaff cutter for different fodders. Michael and ojha (1980) stated that human power is the main source operating small tools and equipments. It was also stated that the number of agricultural workers were 187 million and mentioned that about 20 percent of the total power used in Indian agriculture is from the human source (Anonymous, 1997). Tiwari and Kumar (2011) studied that fodder chopping is done mainly to save storage space, to aid in curing to make the fodder more palatable, to facilitate uniform mixing of concentrates and also to keep the fodder free from spoiling while in storage. The machines used for chopping fodder are called chaff cuter or ensilage cutter or silo filler. Khope and Modak (2013) conducted a study on design of experimental set-up for establishing empirical relationship for chaff cutter energized by human powered flywheel motor.

\section{Materials and Methods}

The study was confined specifically to conduct mechanical studies on agricultural women workers of different age groups for manual chaff cutter operation at College of Agricultural Engineering, Sangareddy. In order to carry out the study, measurement of force that required for cutting the three different fodder and hand cranking capabilities of the operator was conducted with respect to time on hand operated chaff cutter.

\section{Description of hand chaff cutter}

The chaff cutter is a simple but indigenous device, for cutting straw chaff, hay and other green fodder into small pieces before being mixed together with other forage and fed to animals. Chaff cutter is one of the most common agricultural machinery being used in rural area. Chaff cutter performance depends on Output capacity, length of clean cut and operating speed, and is independent of temperature and humidity. The manually hand operated chaff cutter (Sonkhiya Agricultural Industries, Jaipur) was chosen for the study as shown in Fig. 1. Widely demanded in agriculture sector for threshing different kinds of crops, this machine is available in various sizes and designs for our valued patrons.

\section{Features}

High strength

Functional accuracy

Optimum performance

\section{Force requirement}

The force required to cut the chaff could be directly measured by attaching Digital force gauge to the hand operated chaff cutter. Digital force gauge will display the force values in Kg's while operating chaff cutter. Maximum attained values were taken as readings (Fig. 2).

\section{Hand cranking capability}

Number of revolutions were observed as at load condition and at unload condition can be operated by three subjects for different fodders (Fig. 3).

\section{Quantity of cut}

The quantity of fodder cut per hour of operation is calculated by

$\mathrm{W}_{\mathrm{a}}=\frac{60 A}{T}$

Where, $\mathrm{W}_{\mathrm{a}}=$ quantity of cut in $\mathrm{Kg}$

$\mathrm{A}=$ measured the quantity of the cut in $\mathrm{Kg}$ in $\mathrm{T}$ min

$\mathrm{T}=$ duration of operation in $\mathrm{min}$ 


\section{Moisture content of chaff}

For determining the moisture content of green and dry fodder samples weighting $20 \mathrm{~g}$ and 50 $\mathrm{g}$ respectively were taken. The moisture contents were determined by oven dry method by keeping the samples at $70^{\circ} \mathrm{C}$ for 24 hours. The weights of the samples were measured with the help of weighing balance having a least count of $0.1 \mathrm{gm}$. The moisture content of green and dry fodder on wet basis was determined by using following standard formula.

Moisture Content $\%=\frac{\text { weight of wet sample-weight of dry sample }}{\text { weight of wet sample }} \times 100$

\section{Results and Discussion}

This result of experiments conducted to study the physiological responses of agricultural women workers during chaff cutting operation are described below. The performance of chaff cutter for female farm workers was also presented.

\section{Force measurement}

The force required for operation was noted with three different grasses at a fixed time interval during the operation. The force required for cutting of the three different fodders is presented in Table 1. The lowest force required to cut the fodder is Pearl millet $(72.1 \mathrm{~N})$ followed by Jowar $(77.7 \mathrm{~N})$ and Elephant grass $(89.5 \mathrm{~N})$.

The cutting force requirement is changed with the moisture content of the fodder. The
Elephant grasss howed highest moisture content compared to others. But the stem is larger than others, so that immense force is required for cutting of Elephant grass. In case of pearl millet having small size and lower moisture content leads to less force requirement compared to others.

\section{Length of cut}

The data on length of chaff was recorded during cutting of green fodder by female agricultural workers and average values are presented in Table 2. The highest average length of the fodder is obtained for pearl millet followed by Jowar and elephant grass. This may be due to the fact that the variation in the power exerted by the operator to rotate the flywheel of chaff cutter in a fixed time interval.

\section{Hand cranking capabilities}

The hand cranking capabilities for the three different grasses were measured and shown in Table 3. It could be seen that the hand cranking capabilities of all three grasses are good. The cranking capability was lowest in elephant grass at load condition and followed by Jowar and pearl millet. The lowest cranking capability of elephant grass was attributed to maximum power requirement for cutting of grass. Hand cranking capability of pearl millet is higher and so power requirement relatively is less compared to other fodders so that workers could comfortably work with this grass for longer period of times (Fig. 4).

Table.1 Force requirement measured for different fodders

\begin{tabular}{|c|l|c|c|}
\hline S No & Fodders & Force(N) & Moisture content (\%) \\
\hline $\mathbf{1}$ & Jowar & 77.7 & 68.6 \\
\hline $\mathbf{2}$ & Pearl millet & 72.1 & 54 \\
\hline $\mathbf{3}$ & Elephant grass & 89.5 & 75.8 \\
\hline
\end{tabular}


Table.2 Length of cut of different fodders with chaff cutter

\begin{tabular}{|c|l|c|}
\hline S No & \multicolumn{1}{|c|}{ Fodders } & Average length of $\operatorname{cut}(\mathbf{C m})$ \\
\hline $\mathbf{1}$ & Jowar & 1.29 \\
\hline $\mathbf{2}$ & Pearl millet & 1.49 \\
\hline $\mathbf{3}$ & Elephant grass & 1.2 \\
\hline
\end{tabular}

Table.3 Hand cranking capabilities of three subjects with respect to different fodders

\begin{tabular}{|c|c|c|c|c|}
\hline \multirow{2}{*}{ Subjects } & \multicolumn{3}{|c|}{ At load condition } & \multirow{2}{*}{$\begin{array}{c}\text { At no load } \\
\text { condition }\end{array}$} \\
\cline { 2 - 5 } & Jowar & Pearl millet & Elephant grass & 68 \\
\hline $\mathbf{P}_{\mathbf{1}}$ & 47 & 58 & 42 & 73 \\
\hline $\mathbf{P}_{\mathbf{2}}$ & 62 & 62 & 57 & 62 \\
\hline $\mathbf{P}_{\mathbf{3}}$ & 53 & 61 & 45 & \\
\hline
\end{tabular}

Table.4 Number of cuts for one revolution of flywheel

\begin{tabular}{|c|c|c|c|}
\hline Subjects & \multicolumn{3}{|c|}{ Number of cuts } \\
\hline & Jowar & Pearl millet & Elephant Grass \\
\hline $\mathbf{P}_{\mathbf{1}}$ & 94 & 116 & 84 \\
\hline $\mathbf{P}_{\mathbf{2}}$ & 124 & 124 & 114 \\
\hline $\mathbf{P}_{\mathbf{3}}$ & 80 & 122 & 90 \\
\hline
\end{tabular}

Table.5 Capacity of chaff cutter with respect to different fodders

\begin{tabular}{|c|c|c|c|}
\hline Subjects & Jowar & Pearl millet & Elephant grass \\
\hline $\mathbf{P}_{\mathbf{1}}$ & 42.6 & 37.2 & 54 \\
\hline $\mathbf{P}_{\mathbf{2}}$ & 48 & 30.6 & 78 \\
\hline $\mathbf{P}_{\mathbf{3}}$ & 49.8 & 33.6 & 60 \\
\hline
\end{tabular}

Fig.1 Hand driven chaff cutter

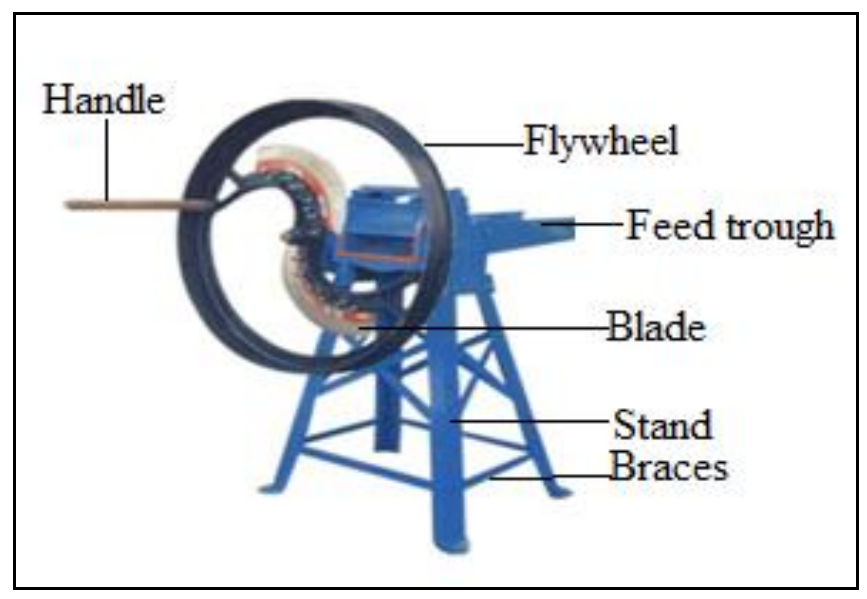


Fig.2 Variation of force requirement for different fodders with moisture content of fodder

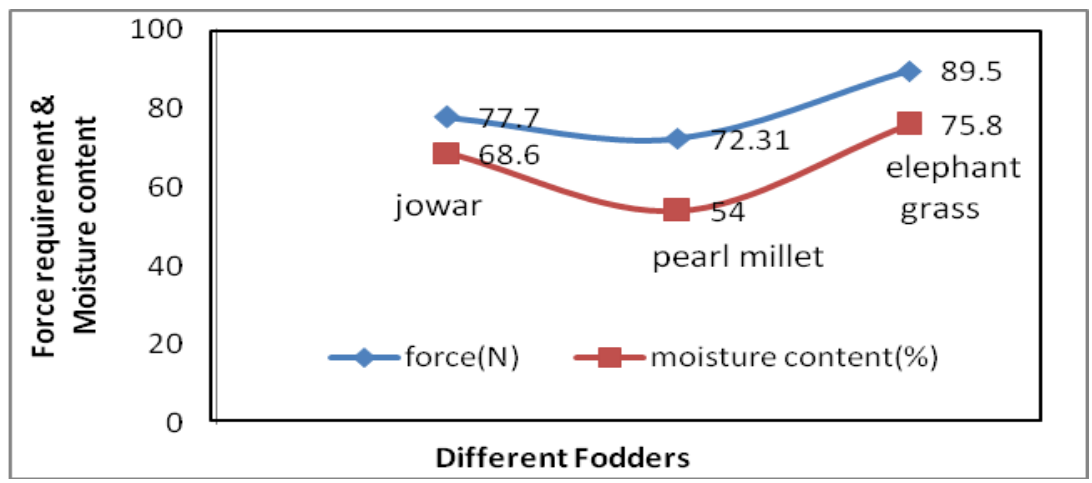

Fig.3 Hand cranking capabilities at load and no load conditions for different fodders

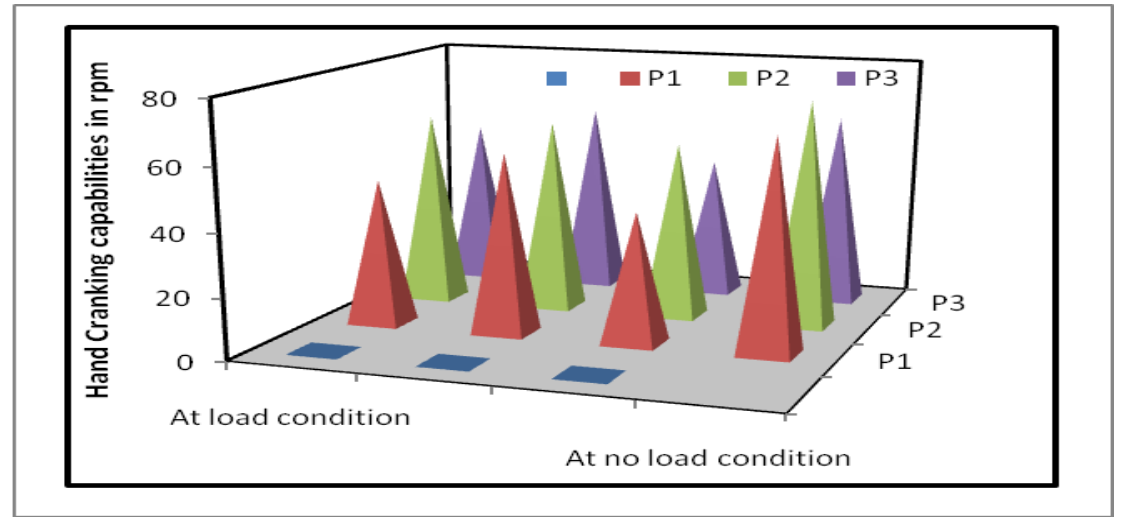

Fig.4 Capacity of chaff cutter with respect to different fodders

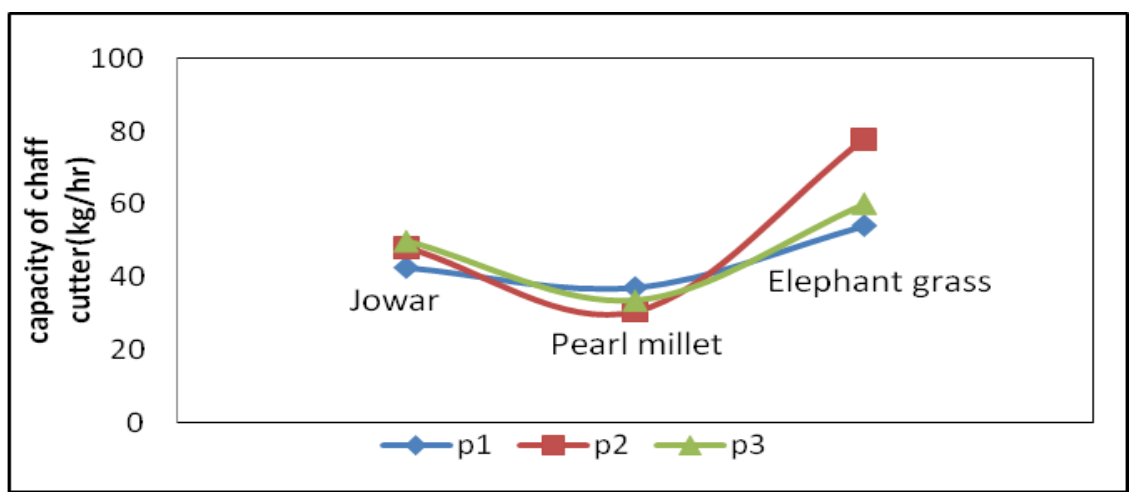

\section{Number of cuts}

The Number of cuts was calculated on the basis of speed of cutter obtained during experimentation. No. of cuts $=$ No. of blades $\mathrm{X}$ No. of revolutions (Table 4).
Since, No. of blades $=2$

Therefore, No. of cuts $=2 \times$ No. of revolutions

\section{Capacity of chaff cutter $(\mathrm{kg} / \mathrm{hr})$}

The capacity of chaff cutter depends upon the length of cut and thickness of grass. It is also 
a function of speed of operation. The variation in the capacities of chaff cutter for different fodders with respect to three age groups is given in Table 5. The maximum capacity of chaff cutter was observed with Subject-3 for Jowar and Subject-2 for elephant grass. The highest capacity of chaff cutter was observed in Subject-2 for elephant grass because the presence of high moisture content and lowest hand cranking capability.

Based on the results of experiments conducted in this study, the following conclusions were drawn. The different mechanical parameters like length of cut, number of cuts, capacity of chaff cutter, hand cranking capabilities and force measurement were measured for the operation of chaff cutter with the three fodder crops. Force requirement increased gradually due to high moisture content of fodders and large size diameter of fodders (Elephant grass $>$ Jowar $>$ Pearl millet: $89.5>77.7>72.1$ N). Hand cranking capabilities of subjects at load conditions gradually decreased compared to at no-load conditions. If hand cranking capabilities of subjects for a particular crop is lower, then the force requirement is found to be high. Number of cuts will increase with the increase in the number of revolutions. Capacity of chaff cutter depends upon length of cut, number of cuts and size of the fodders.

\section{References}

IS: 7897-1975 (Reaffirmed in 2001) - Test code for chaff cutter.

IS: 1511-1979 (Reaffirmed in 2000) Specification for blades for manually operated chaff cutter.

Chauhan, K. M. and Saha, N. P., 2004. Acceptable limits of physiological workload for physically active Indian women, as 11th article. Pp. 163-67.

Davies, A. Duch, W. B.T. and Ibrahim, M.A., 1987. Anthropometric study of Egyptian women. Ergonomics Vol. 30(7): 1089-1098.

Salokhe, V.M. and Mamansari, D.U. 1995. Physical workload during selected farm operations. Journal of human Ergology, Vol. 24(2): 161-169.

Khope, P.B., Modak, J.P., 2013. Design of experimentations for establishing empirical relationship of chaff cutting phenomena energized by human power flywheel motor; J. Agril Advance; 2(5): 158-164.

Mohan, D., Kumar, A., Patel, R. and Varghese, M. 2004. Development of safer fodder cutter machines a case study from North India, J. Safety Science. 42: 43-55.

\section{How to cite this article:}

Akki Sathish, Bangi Nirmala, Rathnapuram Ashwini, Gopathi Anusha and Balachand, Ch. 2020. Measurement of Force Requirement for Manually Operated Chaff Cutter Measurements of Mechanical Parameters. Int.J.Curr.Microbiol.App.Sci. 9(10): 475-480. doi: https://doi.org/10.20546/ijcmas.2020.910.058 